\title{
Bibliometric Analysis of the Research on the Cultivation of Core Values of Contemporary College Students in China
}

\author{
Yan Duan \\ Northeast Normal University \\ Changchun, Jilin Province, China
}

\author{
Huiying Wang \\ Soochow University \\ Suzhou, Jiangsu Province, China
}

\begin{abstract}
Contemporary college students are the bearers and successors of the career of socialism with Chinese characteristics. It is the fundamental task of cultivating core socialist values in the new era to train new people who are responsible for the rejuvenation of the nation. Therefore, to do a good job in cultivating the core values of contemporary college students is related to national development and national rejuvenation. This paper uses bibliometrics method, the Price's law and the Rotka's law to carry on the multi-angle quantitative statistics and the analysis of contemporary university students' core values cultivation research result based on the CNKI retrieval. This paper analyzes the research status and development trend of this field, and puts forward the methods and ideas to further promote the research in this field, so as to provide a reliable quantitative basis for the future scientific development of research on core values cultivation of contemporary college students in China.
\end{abstract}

Keywords-Contemporary college students; Core values; Cultivation; Bibliometrics; Cultivating morality and cultivating people

\section{INTRODUCTION}

It has always been an excellent tradition of the CPC to attach importance to the status and role of youth in national development. President Xi Jinping emphasized, Chinese young people always play a vanguard role in realizing national rejuvenation when he attending the gathering marking the centenary of the May Fourth Movement. At the same time, Xi stressed efforts to strengthen studies of the May Fourth Movement and spirit, and motivate young people to make unremitting contributions to national rejuvenation. Since the 18th CPC national congress, President Xi Jinping took some measures to made great progress in youth work in the new era with the guidance of his "youth outlook". It has attracted extensive attention from the academic circle and all sectors of society to do a good job in the value education of young college students. Obviously, it is of great significance to take this opportunity to review the achievements, experience and deficiencies in cultivating college students' core values over a period of time.

Therefore, on the basis of statistical analysis of the annual distribution, theme distribution, keyword distribution and core author group distribution of contemporary college students 'core values cultivation research, this paper deduces the present situation and trend of the research on the cultivation of the core values of contemporary college students, the key points, hot spots, characteristics and objectives of the research are summarized as well, and then the methods and prospects of further deepening development are put forward. With a view to promoting the new development of the cultivation of the core values of contemporary college students.

\section{SAMPLING AND METHODOLOGY}

This paper makes a statistical analysis of the current research achievements of cultivating college students' core values in CNKI from multiple perspectives by using the method of bibliometrics, and tries to clarify the development context, grasp the research trends and present the current situation of the research on cultivating core values.

Sampling and methodology are as follows: the first step is literature sampling. In this paper, CNKI was used as the data source for literature analysis. The retrieval subject was "college students" and "cultivation of core values". The retrieval literature sources included "journals", "master and doctoral libraries", "conferences" and "newspapers". And finally, 2,936 papers of relevant journals were obtained after reducing the error and repetition of the search results. According to the laws of bibliometrics such as the Rotka's law and the Price's law and with the help of CNKI, CiteSpace classification analysis tools and Excel software, the data were sorted out to explore the current research status and development trend of the research field of cultivating core values of contemporary college students[1]

\section{DATA COLLATION AND QUANTITATIVE ANALYSIS}

Based on widely reading relevant academic achievements, fully grasping the situation of this study, and combining with the feature of the object of this study and the statistical analysis of the annual distribution of journal articles, subject distribution, keyword distribution, core authors distribution and other factors, this paper tries to get the distribution regularity of the research literature of core values of contemporary university students, the development speed, the hot issues, research results tendency and so on, so as to grasp the research status and development trend.

\section{A. Analysis on the Law of Literature Growth: Obviously increasing trend and showing certain stage characteristics}

The law of literature growth is one of the important factors to measure the amount of scientific knowledge. The growth of 
the number of scientific literature can reflect the process and level of a country's technological development.[2]According to the dynamic distribution of annual literature growth shown in Fig. 1, the literature volume of the cultivation of college students' core values shows an obvious increasing trend, but the literature volume of individual annual literature volume declines by a large margin, showing some stage characteristics. Combined with the Price's four-stage literature growth theory, the research of cultivating core values of contemporary university students in China has passed two stages, that is,

"birth period" and "great development period", remains at the third stage "theory gradually achieve maturity period" now, and to complete the fourth stage "theory of completion period" still need to make further efforts.

In the first stage (2005-2012), the number of publications was small, accounting for only $2.11 \%$ of the total. The Opinions on Further Strengthening and Improving the Ideological and Political Education of College Students adopted in 2004 emphasized the strategic significance of strengthening and improving the ideological and political education of college students and training the builders and successors of the career of socialism with Chinese characteristics. However, there is no strong resonance in academia. In 2005, only one article was published, and the study shows a certain lag. In the second stage (2013-2016), in the year of 2012, guided by the thought of "three advocacies", the academia began to pay great attention to the cultivation of socialist core values. With the continuous strengthening of the cognitive basis and grasp degree, the number of published articles increased rapidly, accounting for $63.01 \%$ of the total which was 29.87 times of the number of published articles in the previous stage, the rising trend was obvious. In the third stage (2017-present), although the number of published articles presents instability, the overall maintained a growth trend, with an average annual output of about 690 articles.

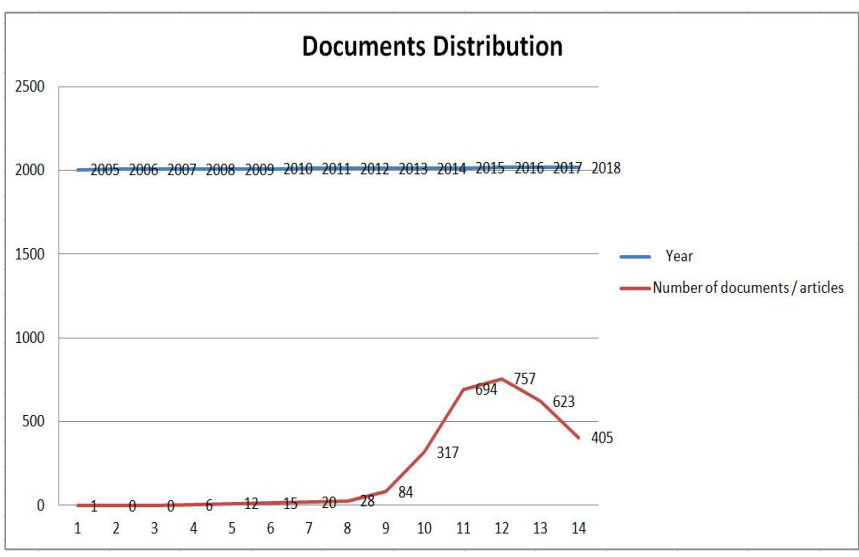

Fig. 1. Trend of the number of articles published in the research field of cultivating core values of contemporary Chinese college students

\section{B. Subject Distribution Analysis: Research on the core values of socialism has become the focus of research}

By analyzing the distribution of the subject, we can get the key points of the research. The analysis found that the subject term "core socialist values" appeared the highest frequency of occurrence, more than 2,460 times, accounting for $40.29 \%$ of the total, which indicates that the research on core socialist values has become the key point. At the same time, the "core socialist values education" and "college students" ranked the second and third place, accounted for $9.43 \%$ and $8.01 \%$ respectively, "college students' core values", "contemporary college students" also occupy the important position, which not only shows the great attention that the academia pay attention to the problem of the core values education of college students but also reveals the dominant status students groups stand in the process of cultivating core values practice. President Xi pointed out that, the value orientation of the youth determines the future value orientation of the whole society, and the youth are still in the period of forming and establishing their values, so it is very important to pay attention to the cultivation of their values in this period.[3]Young college students are the bearers and successors of the future cause of the country, therefore, guiding them to set up correct values in the critical period of their growth is relating to the destiny of our country. At the same time, the key words "world outlook" and "Chinese excellent traditional culture" also indicate the unity of international vision and national characteristics to cultivate college students' core values. In addition, "the approach of cultivation", "new media", "ideological and political education", "ideological and political theory curriculum", "social practice activity" and "campus culture", "efficiency", these keywords highlighted the characteristics of a new era of new media and the importance of the security of network culture, also showing the research on cultivating the path, methods, carriers of the core values of Chinese contemporary college students has become a research focus, and cultivating the core values needs to pay attention to efficacy.

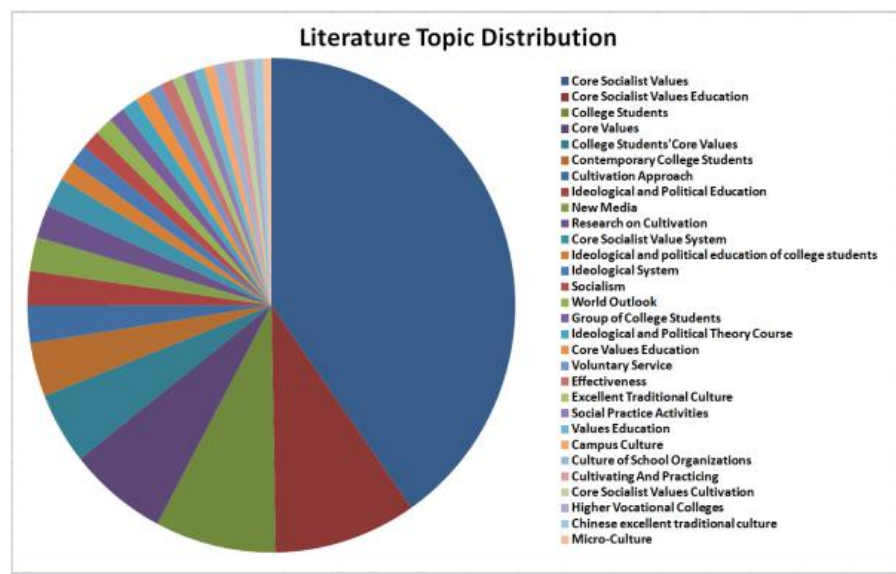

Fig. 2. Literature topic distribution in the research field of core values cultivation of contemporary Chinese college students

\section{Keywords Distribution Analysis: The research on the} cultivation of socialist core values for college students has become a hot research topic

By analyzing the distribution of keywords, we could also get the key points of the research. Keywords in co-occurrence graph (Fig. 3) shows that "core socialist values" and "college students" occupied the main position. They drive the surrounding radiation "ideological and political education", "identity", "practice", "the approach of cultivation", "countermeasures", "college", "new media" and other keywords to make coordinated development and have a more close connection over time. This phenomenon shows that the 
research on the cultivation of core socialist values of college students has become a research focus. The research perspective is diversified and the research is gradually deepened. At the same time, "Chinese dream", "excellent traditional Chinese culture", "red culture" and other keywords have also appeared, highlighting the importance of ideas and beliefs and the direction of "cultivating virtue and cultivating people".

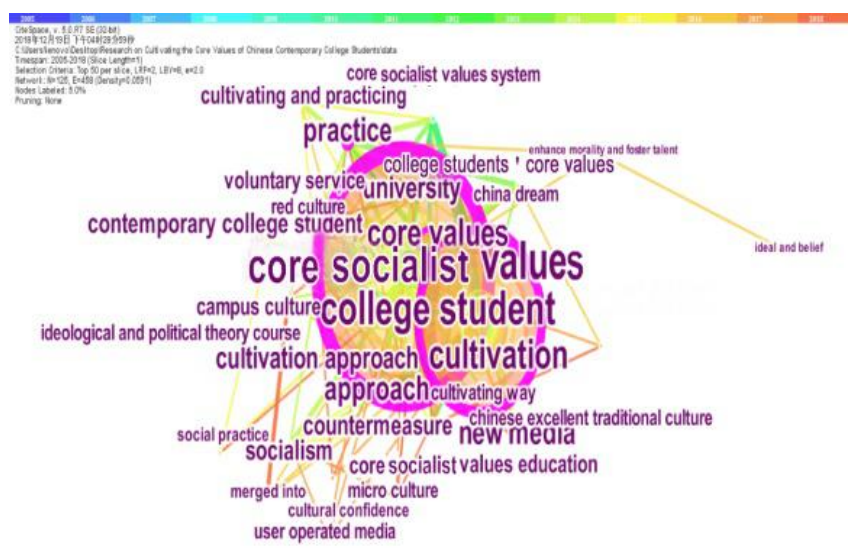

Fig. 3. Co-occurrence map of key words in the field of core values cultivation and research of contemporary Chinese college students

\section{Distribution of Core Author Groups: The stable and independent core author group needs further support and cohesion}

By analyzing the distribution of authors and the scientific productivity of relevant literature can help to judge the research ability of researchers in this field and predict the future research development tendency. Core authors are researchers who have made great contributions to the development of research in this field, and are also important contributors and leaders of academic influence. Whether or not high-quality writers can be formed in this field is a core link to determine whether the research development in this field is mature or not. The Rotka's law states: the number of authors who write $n$ papers is about $\frac{1}{n^{2}}$ of authors who write one paper and the total number of authors who write a paper is about $60 \%$ of the total number of authors. [4]

Among the literature samples retrieved in this study, a total of 2,596 authors were involved, of which 2,339 were authors of one article, accounting for $90.10 \%$ (seriously exceeding $60 \%$ of the benchmark) of all the authors. There were 390 authors publishing two articles, and the proportion of the number of authors who have published one article is only $16.67 \%$ (not up to the standard value). These data show that the research field of cultivating core values of contemporary Chinese college students is not mature yet. There were too many authors who have published only one article, which requires more concentrated research and deeper research. Moreover, a stable and independent core author group has not been formed yet, which needs further support and cohesion. The data shows that there is no significant difference between $16.67 \%$ and $25 \%$ standard values, that is, it is not difficult to achieve this goal, so we should have the motivation and confidence to establish a core author group.

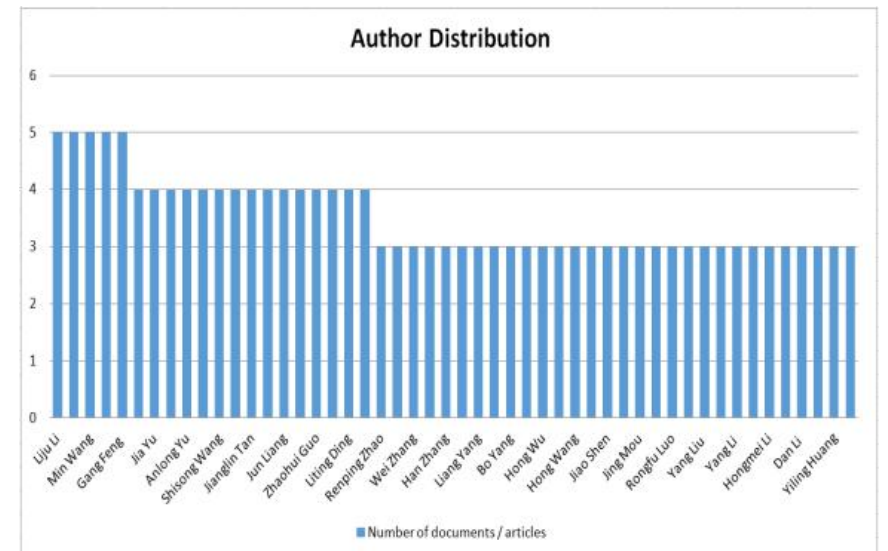

Fig. 4. Author distribution in the research field of core values cultivation of contemporary college students in China

\section{CHALlENGES AND DisCUSSION}

\section{A. Current Situation and Tendency}

In recent years, the research on the cultivation of core values of contemporary college students in China has developed rapidly and achieved a certain result. It is now in the "theory gradually achieve maturity period". The core author group has not been established, and there is still a certain gap before maturity. However, the current development momentum is good, and in the next few years, the number of publications will still show an increasing tendency, but the growth rate will gradually slow down, and eventually reach a relatively stable state, and finally enter the stage of "theoretical completion period", but further efforts are still needed.

\section{B. Key Points and Hot Issues}

The cultivation of core socialist values has become an important and hot research topic in the cultivation of contemporary college students' core values. Nowadays, a theoretical research system has formed with a "core socialist values" as the core, "study on college students" core values", "ideological and political education", "the approach of cultivating core values", "core values of recognition and practice", "core values under the new media era of research" and other key words as the focus of the research. Studies on these hot issues need to be continued and need to be further deepened in the future.

\section{Features and objectives}

Firstly, it trends to practical exploration, which committed to internalizing core socialist values in our hearts and externalizing them in our actions. Secondly, it has formed a developing situation which takes college students as the main body of cultivation, uses the government as the guidance, keeps colleges as the main position, and ideological and political theory courses as the main channel. Thirdly, keeping the ideal and faith as the ideological guidance, cultivating moral tree as the goal, using the traditional culture as the foundation for self-restraint, using "volunteer service" and other practical activities as the practice's cultivation mode has formed, aiming to enhance the practical effect of core values. Fourthly, the environment and carrier of cultivation are diversified. Under the comprehensive effect of "micro-culture", "campus culture" 
and "red culture" environment, a new era environment for the cultivation of core values of Chinese college students has been shaped.

\section{Methods and prospects.}

The research methods and perspectives need to be further developed. From the searched keywords and distribution law of the subject words, the number of quantifications, analysis, empirical investigation, comparison and other key words is extremely few. Only a small number of results can be used to put forward to the analysis of effective details for the purpose of this area and the analysis for the local characteristic development. What's more, how to provide actual core values of developing and practicing the feasibility, accuracy and effectiveness is not strong enough. The innovative perspective expansion, comparative analysis and other studies at home and abroad are relatively scarce, which hinders the exploration of other countries' experience and novel's ideas. Therefore, research needs to focus on these areas so as to achieve long-term development of core values.

\section{CONCLUSION}

In order to deepen the development of core values cultivation research of contemporary college students in China, there are four methods. Firstly, it is necessary to firmly establish the objective of "cultivating morality and cultivating people" and the focus on cultivating new people who are responsible for national rejuvenation. [5] Secondly, we should emphasize the practical subjectivity of college students, pay attention to the level and stage characteristics of college students, and enhance the pertinence and effectiveness of cultivation. Thirdly, we should diversify the ways of cultivation to enhance the appeal and recognition of core values. And finally, more innovative research methods and comprehensive innovative methods are needed to achieve breakthroughs in research, so as to drive the new development of core values cultivation of contemporary college students. Following the path of socialist education with Chinese characteristics and building an education system which comprehensively fosters the students' all-round moral, intellectual, physical and aesthetic grounding with a hard-working spirit.[6]

\section{REFERENCES}

[1] J.P, Xi. "Xi Jinping's Speech at the gathering marking the centenary of the May Fourth Movement," People's Daily, 2019-05-01.(In Chinese)

[2] J.P, Qiu. "Information Metrology," Wuhan University Press, pp. 65,2007. (In Chinese)

[3] J.P, Xi. "Young People Should Consciously Practice Core Socialist Values," People's Daily, 2014-05-05. (In Chinese)

[4] S.S, Luo. "Introduction to Bibliometrics," Bibliographic Literature Publishing House, pp. 100,1987. (In Chinese)

[5] J.P, Xi. "Decisive Victory to Complete the Building of a Moderately Prosperous Society in All Respects and Achieve the Great Victory of Socialism with Chinese Characteristics in the New Era," People's Publishing house, pp.41,2017. (In Chinese)

[6] J.P, Xi. "Following path of socialist education with Chinese characteristics and building an education system which comprehensively fosters the students' all-round moral, intellectual, physical and aesthetic grounding with a hard-working spirit," People's Daily, 2014-09-11. (In Chinese) 